\title{
DESCONSIDERAÇÃO DA PERSONALIDADE JURÍDICA NA LEI ANTICORRUPÇÃO
}

\section{THE DISREGARD OF LEGAL ENTITY IN THE ANTI-CORRUPTION LAW}

\begin{abstract}
ANA LÚCIA BARELLA
Mestranda pelo Programa de Mestrado em Direito Empresarial e Cidadania no Centro Universitário Curitiba - UNICURITIBA.
\end{abstract}

\section{SANDRO MANSUR GIBRAN}

Mestre e doutor em Direito Econômico e Socioambiental, professor do Programa de Mestrado em Direito Empresarial e Cidadania do UNICURITIBA e advogado.

\section{RESUMO}

A pesquisa a seguir se propõe a analisar a Desconsideração da Personalidade Jurídica prevista na Lei 12.846/2013. O estudo iniciar-se-á com a análise da pessoa jurídica e suas teorias e seguirá à Desconsideração da Personalidade Jurídica abordando seu histórico e teorias; em seguida será alvo desta pesquisa a Lei Anticorrupção e a previsão que contém sobre os atos lesivos que a pessoa jurídica não deve cometer sob pena de ser desconsiderada; por fim, este estudo pretende relacionar o instituto da Desconsideração da Personalidade Jurídica à previsão expressa encontrada na Lei em comento. Para tanto serão analisadas diversas bibliografias acerca dos temas.

PALAVRAS-CHAVE: Pessoa Jurídica; Desconsideração da Personalidade Jurídica; Lei Anticorrupção. 


\section{ABSTRACT}

The following research proposes to analyze the Disregard of Legal Entity provided for in Law 12.846 / 2013. The study will begin with the analysis of the legal person and its theories and will follow the Disregard of the Legal Entity addressing its history and theories; then the Anti-Corruption Law will be the subject of this research and the prediction it contains about the unlawful acts that the legal entity should not commit, otherwise it will be disregarded; finally, this study intends to relate the Institute of Disregard of Legal Entity to the express prediction found in the Law in the comment. For this purpose, several bibliographies about the themes will be analyzed.

KEYWORDS: Legal Person; Disregard of Legal Entity; Anti-Corruption Law.

\section{INTRODUÇÃO}

O tema que se pretende abordar na presente pesquisa decorre da própria ideia de pessoa jurídica, posto que tratar-se-á da Desconsideração da Personalidade Jurídica e, como não poderia deixar de ser, a desconsideração é instituto derivado da existência de uma pessoa jurídica.

Para analisar a desconsideração é indispensável compreender a formação da pessoa jurídica enquanto forma e possibilidade de exercício de direitos. Por isso a pesquisa socorrer-se-á aos estudos acerca da pessoa jurídica, de sua evolução por meio de teorias e enquanto oportunizadora do desenvolvimento econômico.

Quando a pessoa jurídica passa a não corresponder aos fins a que se pretende ela pode vir a gerar mais problemas do que os benefícios que oferece à evolução da economia. O meio pelo qual optou-se por combater tais situações foi a utilização da Desconsideração da Personalidade Jurídica.

Esse instituto originou-se da prática dos tribunais norte-americanos e teve sua teoria desenvolvida, principalmente, pelas doutrinas alemã e italiana. No Brasil o instituto começou a ser objeto de estudos a partir de 1969, com a introdução do tema 
pelo paranaense Rubens Requião. A partir de então passaram-se a desenvolver teorias acerca do assunto, culminando no que se tem hoje no ordenamento pátrio.

Dentre uma das previsões da desconsideração na legislação brasileira está a do artigo 14 da Lei 12.846/2013, Lei Anticorrupção.

Esta lei foi resultado de diversos acordos internacionais sobre corrupção e acabou por tomar a pauta do Congresso Nacional depois das manifestações de junho de 2013, representando importante movimento de combate à corrupção neste país.

Depois da abordagem sobre a pessoa jurídica, a Desconsideração da Personalidade Jurídica, a Lei Anticorrupção e os atos lesivos nela previstos, será possível estabelecer-se uma relação entre os tópicos abordados de forma a analisarse a presença do instituto na Lei 12.846/2013, o que servirá de conclusão ao trabalho proposto.

Assim, esta pesquisa justifica-se dada a atualidade das discussões nacionais acerca da corrupção e organiza-se por meio de pesquisa bibliográfica na tentativa de observação do método dedutivo.

\section{PERSONALIDADE JURÍDICA}

O tema da Desconsideração da Personalidade Jurídica (DPJ) passa, inicialmente, pela discussão do conceito e teoria da própria Personalidade Jurídica. Portanto, a pessoa jurídica será aqui abordada para tornar mais claro o estudo acerca da DPJ na Lei Anticorrupção.

Na lição de Marçal Justen Filho (1987, p.19), "até o século XIX e excetuadas as atípicas figuras das companhias ultramarinas, o direito continental desconhecia agrupamentos de pessoas personificados com fins egoísticos".

A Pessoa Jurídica toma forma, historicamente, a partir da ideia de evolução do próprio sistema jurídico. Fábio Konder Comparato (1977, p.248) faz uma revisão crítica do conceito de pessoa jurídica, segundo a qual é necessário analisar essa evolução, considerando que

A ideia de sistema jurídico implica a redução à unidade de uma multiplicidade de elementos, aparentemente desordenados, e representa, como tal, o 


\title{
Personalidade Acadêmica Homenageada:
}

Carlos Aurélio Mota de Souza (Universidade Ibirapuera - UNIB)

grande objetivo das tentativas de explicação do mundo. (...) O conceito fundamental é o mais geral de todos, mas, por isso mesmo, o mais abstrato.

O conceito mais geral de que fala o autor é a expressão pessoa jurídica. Segundo Comparato (1977, p.248), "a sistemática do tipo jurídico foi levada ao extremo pela pandectística alemã, no século passado, e o conceito fundamental, colocado no cume da pirâmide, foi o de direito subjetivo. (...) O verdadeiro direito [seriam] os direitos inatos de todo homem (...)".

Nesse sentido, para Comparato (1977, p.256), a teoria tradicional "identifica o conceito de sujeito de direito com a pessoa (...), [que] não tem direitos e deveres jurídicos, mas simplesmente é o complexo desses deveres jurídicos, é a personificação dessa unidade de deveres, atribuídos ao mesmo indivíduo ou grupo de indivíduos". Assim, tal teoria "conclui que se trata de um instituto análogo ao de pessoa física, uma espécie do gênero 'pessoa' reconhecida como tal pelo legislador ou por ele assim considerada, fictamente".

De acordo com Comparato (1977, p.265), trata-se da teoria ficcionista de Savigny, que

\begin{abstract}
Foi elaborada numa época em que a economia rural procurava libertar-se dos últimos privilégios feudais que a vinculavam, notadamente das corporações de 'mão morta'; enquanto a economia comercial urbana se desembaraçava das remanescentes corporações de artes e ofícios, que entravavam a livre iniciativa empresarial.
\end{abstract}

Nas palavras do José Lamartine Correa de Oliveira (1979, p.6), por conta do que foi exposto, pretendeu-se adequar a teoria da pessoa jurídica a sua época por meio da noção de ficção legal, [que] conferia ao Estado verdadeiro poder criador da pessoa jurídica, o que teve sua expressão máxima no sistema de concessão", uma vez que a personalidade jurídica era concedida pelo Estado. Essa foi a época da Teoria da Ficção Legal da Personalidade Jurídica.

Uma mudança ocorreu na metade do século XIX, segundo Comparato (1977, p.265), quando "Gierke formulou a teoria orgânica" e (JUSTEN FILHO, 1987, p.27) "afirmou a realidade pessoal da pessoa jurídica na acepção de sua identidade ao ser 


\section{Personalidade Acadêmica Homenageada:}

\section{Carlos Aurélio Mota de Souza (Universidade Ibirapuera - UNIB)}

humano"; foi ele quem buscou "defender nela a existência de vontade idêntica à vontade humana", expressão da Teoria da Realidade Objetiva.

Essa teoria aprimorou-se uma vez que a corrente filosófica positivista do século XIX, segundo Comparato (1977, p.261), "acabou influindo, poderosamente, no pensamento jurídico, dando origem a uma tentativa de completa reelaboração das bases metodológicas da ciência do direito". Nessa perspectiva, (COMPARATO, 1977, p.262) "os representantes desse neopositivismo, ou nominalismo jurídico, partem, com efeito, de um enfoque totalmente diverso do 'essencialismo' da ciência jurídica tradicional”. Para eles, segundo o autor (1977, p.264), a expressão pessoa jurídica é um 'símbolo incompleto' já que (JUSTEN FILHO, 1987, p.37) "fora do contexto normativo em que pode vir inserida ela nada indica com precisão", uma vez que "a vontade foi substituída pela norma como fundamento do direito". Teoria que se convencionou chamar de Teoria da Realidade Técnica.

Essa teoria é a adotada pelo Código Civil Brasileiro de 2002, que, mesmo não expressando tal posição em artigo específico, permite essa conclusão da leitura dos artigos 45, 50, 51, 54, VI, 61, 69, 1024, 1033 e 1052, em que são encontradas disposições sobre a constituição e dissolução de pessoas jurídicas, assim como a sua própria desconsideração.

Para Cristiano Chaves de Farias e Nelson Rosenvald (2015, p.132), "pessoa é o sujeito das relações jurídicas que traz consigo um mínimo de proteção fundamental, necessária para realizar tais atividades, compatível e adequada às suas características (que são os direitos da personalidade) ".

De acordo com Flávio Tartuce (2016, p.74), a personalidade, por sua vez, "é a soma de caracteres da pessoa, ou seja, aquilo que ela é para si e para a sociedade". Ou seja, a capacidade seria uma medida da essência, que é a personalidade.

Fábio Konder Comparato (1977, p.268), entende que "a personalização [é] uma técnica jurídica utilizada para se atingirem determinados objetivos práticos autonomia patrimonial, limitação ou supressão de responsabilidades individuais - não cobrindo a esfera toda da subjetividade, em direito".

A separação entre a pessoa jurídica e as pessoas-membro das sociedades é considerada por José Lamartine Correa de Oliveira (1979, p.261) a expressão máxima 
Personalidade Acadêmica Homenageada:
Carlos Aurélio Mota de Souza (Universidade Ibirapuera - UNIB)

da noção de pessoa jurídica. Segundo o autor, existem dois sistemas de separação, o maximalista e o minimalista; aquele exige um limiar máximo de analogia com a pessoa humana, uma vez que "só admite personalidade jurídica no caso das identidades em que a separação se expressou de maneira total, conduzindo à exclusão de responsabilidade dos sócios pelas dívidas da sociedade", enquanto o minimalista, utilizado no Direito Brasileiro, é expresso nos "casos de responsabilidade de sócio por dívida da sociedade [que] configuram hipóteses de responsabilidade por dívida alheia, subsidiária sempre, pois que é pressuposto de sua invocação a insuficiência do patrimônio social", em outras palavras, no sistema maximalista apenas as sociedades com separação total são consideradas pessoas jurídicas; já no minimalista existem situações em que essa separação não ocorre por inteiro, como na Sociedade em Comum ou nas Sociedades em Nome Coletivo. Dito isto, fica claro que o Direito Brasileiro permite a existência de casos em que a responsabilidade seja subsidiária e, portanto, utiliza-se do Sistema Minimalista da Pessoa Jurídica.

Importa apontar, ainda, para a questão levantada por Marçal Justen Filho (1987, p.41) no seu estudo sobre a Desconsideração da Personalidade Jurídica, já que para ele "o principal aspecto da evolução das teorias da pessoa jurídica é a funcionalização deste instituto. Seus parâmetros são extrínsecos: a coletividade e os fins do Estado"; ou seja, o abuso de direito só "é atribuído em função da realização de interesses e valores outros, transcendentes ao individual". Portanto, a existência da pessoa jurídica justifica-se pela função social que exerce ao separar os sócios e a sociedade, permitindo o avanço econômico e social.

Vale ressaltar, derradeiramente, que, apesar das possíveis diferenças teóricas entre os termos pessoa jurídica e personalidade jurídica, esta pesquisa utilizará ambas as expressões como sinônimos, uma vez que as referências bibliográficas que fundamentam a presente pesquisa não fazem distinção entre os termos ao tratarem da 'desconsideração de personalidade jurídica' ou de 'desconsiderar-se a pessoa jurídica'. 


\title{
Personalidade Acadêmica Homenageada:
}

Carlos Aurélio Mota de Souza (Universidade Ibirapuera - UNIB)

\subsection{DESCONSIDERAÇÃO DA PERSONALIDADE JURÍDICA}

O estudo do tema Pessoa Jurídica, desenvolvido no item anterior, embasa a pesquisa sobre sua Desconsideração da Personalidade Jurídica à medida que apenas por meio do reconhecimento da separação entre a sociedade e os sócios é que se pode pretender o inverso: a desconsideração dessa separação.

No Brasil, o responsável por introduzir o tema ao debate foi Rubens Requião, em 1969, numa Conferência proferida na Universidade Federal do Paraná por ocasião do primeiro centenário de aniversário do Desembargador Vieira Cavalcanti Filho, fundador da Faculdade e seu primeiro catedrático do Direito Comercial.

Naquela ocasião, Requião (1969, p.13) introduziu o assunto e cunhou a expressão 'Desconsideração da Personalidade Jurídica', como pode-se observar no trecho a seguir de seu discurso:

\begin{abstract}
A doutrina desenvolvida pelos tribunais norte-americanos, da qual partiu o Prof. Rolf Serick para compará-la com a moderna jurisprudência dos tribunais alemães, visa a impedir a fraude ou abuso através da personalidade jurídica, e é conhecida pela designação 'disregard of legal entity' ou também pelo 'lifting the corporate veil'. Com permissão dos mais versados no idioma inglês, acreditamos que não pecaríamos se traduzíssemos as expressões referidas como 'desconsideração da personalidade jurídica' ou ainda como 'desestimação da personalidade jurídica' (...).
\end{abstract}

Além das doutrinas norte-americana e alemã, citadas pelo autor, pode-se inserir a italiana entre as primeiras doutrinas a preocupar-se com o assunto. Vejamos a contribuição de cada uma.

$\mathrm{Na}$ doutrina norte-americana, explica Oliveira (1979, p.266-7) que a evolução para um novo sistema em que a personalidade jurídica não fosse uma concessão do Estado às Corporation (entidades reconhecidas pelo Estado através da incorporation ${ }^{1}$ ) começou em Nova York, em 1811 para estimular determinadas atividades produtivas.

\footnotetext{
1 Em tal sistema, não tem o menor interesse a distinção entre sociedades comerciais e sociedades civis. A distinção entre sociedades 'de fins lucrativos' e os grupos de objetivos não-lucrativos (associações) só apresenta relevância do ponto de vista do Direito Tributário, pois que a 'incorporação' pode ter por objeto tanto uma entidade de fins lucrativos quanto uma entidade que, em nosso Direito, seria uma associação. Tem, ao contrário, a maior importância, a distinção entre sociedades não incorporadas e sociedades incorporadas, pois só as últimas são consideradas dotadas de personalidade jurídica. OLIVEIRA, 1979, p. 265
} 
Personalidade Acadêmica Homenageada:
Carlos Aurélio Mota de Souza (Universidade Ibirapuera - UNIB)

O autor (OLIVEIRA, 1979, p.270) aponta duas fases na evolução do pensamento norte-americano quanto ao modo de descrever e fundamentar a desconsideração:

Na primeira fase, toda a atenção é dada ao fato da desconsideração, mas seus pressupostos permanecem mergulhados na escuridão. (...). Numa segunda fase(...) a questão passa a ser colocada de modo mais profundo, de modo a pesquisar-se quais os pressupostos que poderiam ser exigidos para que a personalidade propriamente, neste ou naquele caso, pudesse ser desconsiderada.

Para Fábio Ulhoa Coelho (1989, p.30), a aplicação da teoria da desconsideração da personalidade jurídica no direito norte-americano, "é feita sem a preocupação, presente no Direito Inglês, de encontrar o fundamento técnico que autorize o desprezo da forma".

A comparação entre o Direito Americano e o Inglês verificada no trecho acima, segundo Coelho, partiu dos estudos do italiano Pierro Verrucoli acerca da DPJ. Sobre o italiano, Coelho (1989, p.24) explica que comparou o reconhecimento da personalidade jurídica nos direitos italiano, inglês e norte-americano "para concluir pela caracterização da personalidade jurídica das pessoas jurídicas como um privilégio".

A visão da pessoa jurídica como privilégio está intimamente ligada a sua compreensão como concessão do Estado, relativa à teoria da pessoa jurídica como ficção. A evolução das teorias da personalidade jurídica, conforme os apontamentos feitos no item anterior, possibilitam percepções diferentes da própria desconsideração.

Segundo Coelho (1989, p.32), a conclusão a que Verrucoli chega encontra-se no fato de que tanto para o Direito Americano quanto para o Inglês a personalidade jurídica é um privilégio; e que a diferença entre ambos está no fato de que a Common Law não se preocupa com a precisa definição de uma teoria sistematizadora, a partir da qual fosse autorizada a DPJ, enquanto a Civil Law tem essa preocupação bem acentuada.

A respeito da doutrina alemã, Oliveira utiliza-se, na obra 'A dupla crise da personalidade jurídica', dos estudos do alemão Rolf Serick, cuja teoria decorre de comparações entre a doutrina alemã e a norte-americana. Segundo a obra em estudo, 


\section{Personalidade Acadêmica Homenageada:}

Carlos Aurélio Mota de Souza (Universidade Ibirapuera - UNIB)

Serick pretendeu solucionar o problema dos critérios para ocorrência da Desconsideração da Personalidade Jurídica por meio de quatro hipóteses ou princípios em que a teoria poderia ser aplicada.

De acordo com Fábio Ulhoa Coelho (1989, p.17), o primeiro princípio ocorre se a forma da pessoa jurídica for abusada. Oliveira (1979, p.273) chamou este princípio de "hipótese de fraude à lei". O segundo princípio, (OLIVEIRA, 1979, p.274) "casos de fraude a obrigações contratuais" é, segundo Coelho (1989, p.19), o uso da pessoa jurídica com intuito de descumprir obrigações contratuais.

O terceiro princípio, (OLIVEIRA, 1979, p.274) "fraude contra credores", "através da transferência de bens do devedor ". Casos de confusão patrimonial, por exemplo. Por derradeiro, o quarto princípio trata da hipótese de (OLIVEIRA, 1979, p.275) "vinculação entre duas sociedades", ou seja, confusão entre elas. Nessa hipótese, conforme explica Coelho (1989, p.22), "se o legislador previu certa disciplina jurídica a casos em que as partes de um negócio devem ser distintas, será jurídica a desconsideração da autonomia da pessoa jurídica que realiza negócios com integrante seu".

A partir de estudos das doutrinas estrangeiras, lentamente o Brasil passou a construir seus próprios conceitos sobre o assunto. Como já mencionado, um dos precursores foi Rubens Requião, que teve como base os estudos de Serick e Verrucoli.

Outro foi José Lamartine Correa de Oliveira (1979, p.610-11), com a obra supracitada 'A dupla crise da Personalidade Jurídica', nela o autor relaciona a desconsideração diretamente à responsabilidade subsidiária dos sócios ao afirmar que "para que se possa falar de verdadeira técnica desconsiderante, em tema de responsabilidade, será necessária a presença do princípio da subsidiariedade (...)".

Marçal Justen Filho (1987, p.57) discorda de Oliveira posto que, para ele, "a desconsideração se passa em nível de funcionamento do instituto jurídico, tem-se em mente 0 desvio de resultado que seria propiciado se não efetivada a desconsideração"; assim, "a correspondência a uma função é, então, indispensável para a construção do conceito de desconsideração". Nesse sentido, a discordância 


\section{Personalidade Acadêmica Homenageada: \\ Carlos Aurélio Mota de Souza (Universidade Ibirapuera - UNIB)}

com Oliveira reside no fato de que faz distinção nas operações, não na função da personalidade jurídica.

De acordo com Justen Filho (1987, p.65), "as manifestações da desconsideração são múltiplas (...) [donde se conclui pela] inexistência de um único e específico fundamento jurídico para a aplicação da teoria”. Ele (JUSTEN FILHO, 1987, p.67) elabora um conceito genérico de desconsideração da personalidade jurídica, segundo o qual "a desconsideração corresponde à ignorância ou não aplicação, para os casos concretos, do regime jurídico estabelecido como regra para situações de que participe uma sociedade personificada (pessoa jurídica) ".

O conceito de DPJ de Justen Filho pretende ser utilizado por meio de pressupostos que são buscados na última parte da obra. Nesse sentido, para ele (1987, p.135), os limites ou pressupostos para aplicação do instituto da desconsideração da personalidade jurídica variam segundo a função esperada para a pessoa jurídica no contexto em que se encontrar, os pressupostos têm natureza funcional.

Outra teoria que faz distinção diversa é a de Fábio Konder Comparato (1977, .274-5), a partir da obra 'O poder de Controle na Sociedade Anônima'. Segundo ele,

O verdadeiro critério no assunto é o referencial aos próprios pressupostos da separação patrimonial, enquanto causa da constituição das sociedades (...). A falta de qualquer um desses pressupostos torna ineficaz a separação de patrimônio, estabelecida em regra.

Esclarece o autor (1977, p.271) que os pressupostos a que se refere são os formais, estabelecidos em lei, e os específicos relacionados ao desaparecimento do objeto social ou quando este se confunde com a atividade ou interesse de determinado sócio.

Segundo Coelho (1989, p.41), Comparato rejeita o subjetivismo dos critérios de Serick e inaugura uma teoria objetiva. $O$ autor critica a formulação objetiva de Comparato ao desenvolver sua própria teoria. Para tanto, Coelho (1989, p.54) afirma que existem duas formulações para a teoria da desconsideração: "a formulação subjetiva, em que importa, em regra, a ocorrência da intenção fraudulenta no uso da 


\section{Personalidade Acadêmica Homenageada: \\ Carlos Aurélio Mota de Souza (Universidade Ibirapuera - UNIB)}

pessoa jurídica com dano a terceiros e a formulação objetiva, onde não há nenhuma importância conferida a este elemento".

Ao distingui-las Coelho propõe uma teoria que não dê tanta ênfase ao elemento intencional, como na teoria de Serick, mas não o exclua por completo, como na de Comparato. O próprio autor (1989, p.55) considera sua teoria como "algo intermediário entre as duas formulações" e a estabelece nos seguintes termos: (1989, p.92) "o juiz pode decretar a suspensão episódica da eficácia do ato constitutivo se verificar que ela foi utilizada como instrumento para a realização de fraude ou abuso de direito".

No entanto, além das teorias acima descritas, Fábio Ulhoa Coelho propôs uma segunda distinção chamando as possibilidades de aplicação do instituto de teoria maior e menor da DPJ. A respeito do assunto tratam Cristiano Chaves de Farias e Nelson Rosenvald (2015, p.393):

[...] para a teoria maior, a desconsideração depende de requisito específico, razão pela qual nem todo caso de responsabilização pessoal do sócio configura hipótese de incidência do disregard doctrine, enquanto a teoria menor considera que toda e qualquer hipótese de responsabilização do sócio por dívida da empresa é um caso de desconsideração. De qualquer sorte, a teoria maior exigirá, sempre, o atendimento de requisitos legais específicos para efetivar a desconsideração. De outra banda, a teoria menor ${ }^{2}$ [...] fundamenta o seu cerne no simples prejuízo do credor para afastar a autonomia patrimonial da pessoa jurídica.

Pode-se extrair do trecho acima que a teoria maior se utiliza de requisitos para configuração de possibilidade de se desconsiderar uma pessoa jurídica. Tais requisitos estão previstos no artigo 50 do Código Civil de 2002, que determina como pressuposto para aplicação a ocorrência de abuso da personalidade jurídica, sendo este caracterizado pelo desvio de finalidade da pessoa jurídica ou pela confusão patrimonial entre a sociedade e seus sócios.

Com relação à teoria menor verifica-se que não se requer nenhum pressuposto que não seja o fato de que a sociedade, enquanto pessoa jurídica, não percebendo créditos para saldar suas dívidas, sirva de obstáculo ao pagamento de

\footnotetext{
${ }^{2}$ Cf. COELHO, 1989 , p. 54-63
} 


\section{Personalidade Acadêmica Homenageada:}

Carlos Aurélio Mota de Souza (Universidade Ibirapuera - UNIB)

seus credores. Esta hipótese está prevista no artigo 28, §5 do Código de Defesa do Consumidor.

Conclui-se, assim, o presente capítulo, cujo objetivo foi o de apresentar um panorama histórico da Desconsideração da Personalidade Jurídica tangenciando questões como as teorias subjetiva, subjetiva mitigada e objetiva, assim como as teorias maior e menor de aplicação do instituto.

Os estudos seguem a partir de breve análise da Lei Anticorrupção, que, posteriormente, será relacionada ao tema aqui abordado.

\section{A LEI ANTICORRUPÇÃO}

Acerca do problema da corrupção, pode-se afirmar que sua ocorrência é de tão longa data que é possível conferir um início remoto no Antigo Egito, quando a arrecadação de impostos fez surgir a necessidade de análise dos controles de sua arrecadação. Com o capitalismo essa análise transformou-se em auditorias, ligadas a contadores - que formaram associações entre 1880 e 1900 na Europa e nos Estados Unidos. Mais tarde foram aplicadas regras próprias a essa atividade, desvinculandose a atividade de auditoria das atividades contábeis (SILVA, 2016, p. 28). Desde então esforços são feitos na tentativa de combater a corrupção, como a Lei 12.846/2013.

Essa lei, conhecida como Lei Anticorrupção (LAC) ou Lei da Empresa Limpa, surgiu no contexto das manifestações de rua que ocorreram em junho de 2013, "realizadas em todas as grandes e médias cidades brasileiras, que apontaram, dentre outras questões cruciais, a corrupção generalizada, nos planos federal, estadual e municipal, abrangendo os diversos níveis da administração" (CARVALHOSA, 2014).

A insatisfação popular com os episódios de corrupção agravou-se a partir de 2005, quando o Brasil "vivenciou um grande escândalo de pagamento de propinas, conhecido popularmente por Mensalão3" (SILVA, 2016, p.30).

\footnotetext{
3 Processo de investigação de recebimento de propinas por deputados da "base aliada" do Governo Federal, em caráter periódico, objetivando a aprovação de projetos originários do Poder Executivo, vinculados ao Partido dos Trabalhadores
} 


\section{Personalidade Acadêmica Homenageada:}

Carlos Aurélio Mota de Souza (Universidade Ibirapuera - UNIB)

A expectativa de uma legislação de combate à Corrupção "era alimentada desde assinatura pelo Brasil da Convenção das Nações Unidas contra Corrupção, na cidade de Mérida, no México, em 15 de dezembro de 2003" (KICHILESKI; REIS, 2016, p.121), principalmente, mas também desde a "Convenção sobre o Combate da Corrupção de Funcionários Públicos Estrangeiros em Transações Comerciais Internacionais, concluída em Paris em 17 de dezembro de 1997" (FERREIRA; BERTONCINI, 2016, p.457) e da "Convenção Interamericana contra a Corrupção, adotada em Caracas, em 29 de março de 1996, pelos Estados Membros da Organização dos Estados Americanos, aprovada pelo Congresso Nacional em 25 de junho de 2002 e promulgada pelo Decreto 4.410, de 7 de outubro de 2002" (BERTONCINI, p. 2).

No entanto, foi a iniciativa popular, por meio das manifestações, que impulsionou a promulgação de uma lei de combate à corrupção, uma vez que pressionou o Congresso Nacional e esse "tentou dar uma resposta positiva à sociedade brasileira com a elaboração da lei 12.846/2013, frente a impunidade e pandemia de corrupção enfrentada no país" (KICHILESKI; REIS, 2016. p. 121). Esta lei é fruto do Projeto de Lei 6.826/2010, construído com vistas a atender aos compromissos assumidos pelo Brasil nas convenções acima citadas.

Patrícia de Toledo Campos (2015, p.161) corrobora com esse entendimento quando esclarece que

O Projeto de Lei no. $6.826 / 2010$ proposto pela Controladoria Geral da União
em 18 de fevereiro 2010, com objetivo de assegurar garantias de lisura aos
eventos internacionais a serem realizados no Brasil, foi aprovado na Câmara
dos Deputados em maio de 2011 . Porém, desde 2013 estava paralisado no
Senado. Somente após inúmeros e intensos protestos realizados no mês de
junho é que obteve regime de tramitação de prioridade e foi aprovado em 05
de julho de 2013 , sendo transformado na Lei Ordinária no $12.846 / 2013$ em 02
de agosto de 2013 .

Clóvis Alberto Bertolini Pinho (2015, p.384) afirma que a lei "tem o objetivo legítimo de reduzir e punir essas práticas que corrompem a estrutura estatal e que diminuem as possibilidades de uma boa prestação administrativa"; e pretende, de acordo com Campos (2015, p.163), preencher a ausência de normas no sistema jurídico brasileiro "sobre a responsabilização administrativa e civil de pessoas jurídicas que praticam atos ilícitos em desfavor da Administração Pública nacional e 
estrangeira, principalmente, atos de corrupção e fraude em licitações e contratos administrativos".

Objetivamente, a LAC é constituída pelos seguintes sete capítulos: I Disposições Gerais, II - Dos atos lesivos à Administração Pública nacional ou estrangeira, III - Da responsabilização administrativa, IV - Do processo administrativo de responsabilização, $\mathrm{V}$ - Do acordo de leniência, VI - Da responsabilização judicial e VII - Disposições Finais.

Tratar do tema da Desconsideração da Personalidade Jurídica prevista no artigo 14, Capítulo IV não implica observar apenas esse artigo determinado, mas avaliar os atos lesivos que, se praticados, podem ter como consequência a DPJ. Nesse sentido, a pesquisa discorrerá a respeito de tais atos, previstos em capítulo específico da lei, tamanha sua importância.

\subsection{ATOS LESIVOS}

Os atos lesivos são enumerados na Lei 12.846/2013 em seu Capítulo IV, artigo 5으, que, de acordo com Pinho (2015, p.387), apresenta

Uma série de condutas que serão objeto de condenação no âmbito da Administração Pública, posto que estas condutas estabelecidas possuem correspondentes na Lei de Licitações, inclusive, com a mesma redação, depreendendo-se, assim, que determinadas condutas poderão ser punidas em três esferas: a penal, a administrativa e a civil.

Nos termos da lição de Mateus Bertoncini (2015, 153-4), os referidos atos lesivos constam na Lei Anticorrupção

a título de cumprir com a Convenção sobre o Combate da Corrupção de Funcionários Públicos Estrangeiros, o Brasil providenciou a reforma de seu Código Penal por intermédio da Lei 10.467, de 11.06.2002, que inseriu o Capítulo II-A neste diploma, intitulado "Dos crimes praticados por particular contra a administração pública estrangeira", definindo os delitos de "corrupção ativa em transação comercial internacional" (art. 337-B) e de "Tráfico de influência em transação comercial internacional" (337-C), além de estabelecer o conceito de "funcionário público estrangeiro" no art. 337-D. Ou seja, a Lei 10.467/2002 cuidou da pessoa física autora dos aludidos crimes, enquanto a Lei 12.846/2013 teve como foco a pessoa jurídica, ambas em atendimento à referida convenção internacional. (Grifo nosso) 


\title{
Personalidade Acadêmica Homenageada:
}

Carlos Aurélio Mota de Souza (Universidade Ibirapuera - UNIB)

No que concerne à distinção entre os sujeitos pessoa física ou jurídica vale ressaltar que "o referido diploma legal instituiu entre nós uma nova forma de responsabilidade, a responsabilidade da pessoa jurídica pela prática de atos lesivos à administração pública, nacional ou estrangeira" (BERTONCINI, 2015, p.156). Tal pessoa jurídica comete crime à medida que incorre nos atos lesivos definidos pelo artigo $5^{\circ}$ da LAC.

Sobre a responsabilidade na Lei $12.846 / 2013$, Diego do Nascimento Kiçula (2017, p.61) afirma que

\begin{abstract}
Em verdade, o novel legal dá à responsabilidade duplo tratamento. Isso porque, enquanto a Lei impõe o caráter objetivo na responsabilização das pessoas jurídicas em razão da prática de uma das condutas descritas nos incisos do artigo $5^{\circ}$ e prevê, de forma independente e autônoma, que as pessoas naturais serão punidas na medida de sua culpabilidade, nos termos do art. 3 o da referida Lei (...).
\end{abstract}

Segundo o autor (KIÇULA, 2017, p. 62), a responsabilização objetiva tem duas funções: " (i) estabelecer um mecanismo que permita sancionar a pessoa jurídica sem que se adentre na questão da culpa no ato, o que é de difícil comprovação; (ii) dar celeridade e efetividade às punições impostas por força da presente Lei".

Para Kichileski e Reis (2016, p.133), "é possível conceituar os atos lesivos do art. 5 da lei 12.846/2013 como os atos típicos, antijurídicos e objetivamente imputáveis à pessoa jurídica (...)". Para Ferreira e Bertoncini (2016, p.453), "segundo a Lei, os atos lesivos à administração pública, nacional ou estrangeira, definidos em seu art. 5º, estão sujeitos à "responsabilização administrativa" (arts. $6^{\circ}$ a 15$)$ e à "responsabilização judicial" (arts. 18 a 21)".

No tocante à separação entre as sanções administrativa e civil, Bertoncini (2015, p.157) entende que

[...] o mais apropriado parece ser entender que o novo diploma legal instituiu entre nós - repita-se - uma nova forma de responsabilidade, a "responsabilidade da pessoa jurídica pela prática de atos lesivos à administração pública, nacional ou estrangeira", sujeita a um regime jurídico próprio, que inova ao estabelecer para o mesmo ilícito dois blocos de sanções: as penalidades do art. 6.. , aplicáveis por intermédio do processo administrativo; e as medidas punitivas do art. 19, aplicáveis com base em uma ação civil pública. $O$ melhor é se falar em sanções, sem qualquer 


\section{Personalidade Acadêmica Homenageada:}

Carlos Aurélio Mota de Souza (Universidade Ibirapuera - UNIB)

adjetivação, até porque as tais sanções "administrativas" podem incidir na via judicial.

Para o autor (BERTONCINI, 2015, p.157), os atos lesivos são típicos, devendo estar previstos, donde decorrem duas consequências: sua previsão na LAC é exaustiva e a tentativa não é punida; são antijurídicos posto que atentam contra bens jurídicos protegidos pelo Direito (patrimônio público); são objetivamente imputáveis à pessoa jurídica, desde que demonstrado o nexo de causalidade entre o ato e o resultado; sua caracterização é objetiva, não exigindo comprovação de dolo ou culpa.

Importa para a presente pesquisa o fato de que a pessoa jurídica que cometer um dos atos lesivos previstos na Lei Anticorrupção poderá ser responsabilizada. Nesse sentido, vale ressaltar que esta pesquisa está voltada ao instituto da Desconsideração da Personalidade Jurídica independentemente do tipo de processo, se administrativo ou civil, isto porque o que se pretende discutir é a aplicação material do instituto, como previsto na referida $L A C$.

Assim, encerra-se este capítulo concluindo-se que a ocorrência dos atos lesivos previstos na LAC é indispensável para a aplicação da DPJ às pessoas jurídicas envolvidas. Este será o tema do item que segue.

\section{DESCONSIDERAÇÃo DA PERSONALIDADE JURÍDICA NA LEI ANTICORRUPÇÃO}

Depois da análise da pessoa jurídica e sua evolução é possível perceber que o surgimento de sua desconsideração é uma consequência da má utilização dessa representação. Umas das formas de se evitar essa situação é a previsão legal da DPJ, como acontece com a Lei Anticorrupção. 


\section{Personalidade Acadêmica Homenageada:}

Carlos Aurélio Mota de Souza (Universidade Ibirapuera - UNIB)

Esta Lei, a 12.846/2013, dispõe, segundo seu primeiro artigo, sobre a responsabilidade objetiva das pessoas jurídica elencadas em seu parágrafo único, in verbis:

Art. 10 Esta Lei dispõe sobre a responsabilização objetiva administrativa e civil de pessoas jurídicas pela prática de atos contra a administração pública, nacional ou estrangeira. Parágrafo único. Aplica-se o disposto nesta Lei às sociedades empresárias e às sociedades simples, personificadas ou não, independentemente da forma de organização ou modelo societário adotado, bem como a quaisquer fundações, associações de entidades ou pessoas, ou sociedades estrangeiras, que tenham sede, filial ou representação no território brasileiro, constituídas de fato ou de direito, ainda que temporariamente.

Caso fosse realizada uma leitura literal do artigo acima transcrito, incorreríamos em excessos e ausências no que tange à Desconsideração da Personalidade Jurídica porque a redação deste artigo não parece a melhor e mais clara possível, conforme aponta Ubirajara Costódio Filho (2015, p.81) ao sugerir que

[...] soa mais apropriado concluir que o legislador laborou mal na redação desse dispositivo, o qual há de ser compreendido como se assim anunciado: 'Aplica-se o disposto nesta Lei às pessoas jurídicas de direito privado, de qualquer natureza, personificadas ou não, nacionais ou estrangeiras.

Segundo o autor (2015, p.74), "todas as sociedades personificadas (...) são destinatárias da Lei 12.846/2013, mas o mesmo não se pode dizer das sociedades sem personalidade jurídica"; ainda, afirma que "como o foco principal da Lei Anticorrupção são as pessoas jurídicas, não se entende porque o legislador resolveu mencionar as sociedades 'constituídas de fato' no parágrafo único do art. $1^{0 ”}$.

Costódio Filho (2015, p.78-80) também aponta problemas na indicação de sociedades estrangeiras, uma vez que, tendo sede no Brasil, são consideradas nacionais; ainda, trata da falta de previsão de organizações religiosas, partidos políticos, empresas individuais de responsabilidade limitada e empresas estatais que podem figurar como cometedoras dos atos lesivos previstos na LAC.

O autor (2015, p.82) afirma que a melhor opção é "uma interpretação com viés teleológico e sistemático" para que o texto legal possa combater "pessoas jurídicas em geral' que pratiquem atos de corrupção, garantindo ao artigo "capacidade de resistir a eventuais mudanças legislativas no direito civil brasileiro, em caso de criação 
ou supressão de dada modalidade de pessoa jurídica naquela lisa do artigo 44 do CC/2002".

No entanto, apesar da redação a respeito de seus sujeitos passivos, inova a Lei Anticorrupção ao dirigir a desconsideração às pessoas jurídicas estabelecendo sua responsabilidade de forma objetiva, isto porque pretende resolver o problema da corrupção não apenas pela via dos dirigentes, mas atingindo seus negócios, a pessoa jurídica em si.

A previsão expressa de desconsideração encontra-se no artigo 14, a seguir transcrito:

\begin{abstract}
Art. 14. A personalidade jurídica poderá ser desconsiderada sempre que utilizada com abuso do direito para facilitar, encobrir ou dissimular a prática dos atos ilícitos previstos nesta Lei ou para provocar confusão patrimonial, sendo estendidos todos os efeitos das sanções aplicadas à pessoa jurídica aos seus administradores e sócios com poderes de administração, observados o contraditório e a ampla defesa.
\end{abstract}

De acordo com os estudos acima desenvolvidos sobre o tema é possível afirmar que a DPJ descrita neste artigo utiliza a teoria maior, subjetiva, dependente de critérios para sua aplicação.

Como critério pode ser observada a necessidade de incursão em abuso da pessoa jurídica para o cometimento de atos de corrupção, da mesma forma como a ocorrência de confusão patrimonial. Mas o mais importante é que tais condutas devem pretender facilitar, encobrir ou dissimular a prática dos atos lesivos previstos no art. $5^{\circ}$, fonte de estudos do item 3 desta pesquisa.

A partir desta relação, importa registrar que não se trata de todo ou qualquer abuso da pessoa jurídica, mas aqueles ligados aos atos previstos na própria LAC. Sobre o tema, José Anacleto Abduch Santos $(2015,275)$ afirma que

\footnotetext{
A Lei Anticorrupção dá um contorno jurídico próprio para o abuso de direito que pode ensejar a desconsideração da personalidade jurídica. Poderá haver a desconsideração sempre que utilizada a personalidade jurídica para facilitar, encobrir ou dissimular a prática dos atos ilícitos previstos na lei ou para provocar confusão patrimonial.
}

Neste sentido é a afirmação do autor (SANTOS, 2015, p.273) de que: 


\section{Personalidade Acadêmica Homenageada:}

Carlos Aurélio Mota de Souza (Universidade Ibirapuera - UNIB)

[...] o manto protetor da pessoa jurídica somente operará efeitos se, e somente se, a conduta dos sócios ou dirigentes da pessoa jurídica se mantiver nos limites da legalidade e da legitimidade.

Quanto aos referidos limites de legalidade, apontamos, por meio de Bertoncini, 2015, no item 3.1, que os atos lesivos são típicos, assim, devem estar previstos na lei. Ou seja, a abusividade ou confusão patrimonial que pode ensejar a aplicação da DPJ, segundo a LAC, deve estar diretamente relacionada aos atos previstos nesta mesma lei.

A discussão que se propõe nesta pesquisa está voltada aos aspectos materiais de aplicação da DPJ, por isso mesmo, relativa à utilização, ou não, de critérios para sua ocorrência e, existindo, quais seriam.

Conforme exposto no item 2.1, a Desconsideração da Personalidade Jurídica tem como objetivo a responsabilização do sócio que incorreu em ilícito, por isso o véu da personalidade jurídica é apenas levantado com o fim de encontrar o sócio causador do abuso ou confusão patrimonial.

No caso da LAC, o art. 14 vai muito além do levantar do véu porque a DPJ responsabilizará os dirigentes/sócios que inobservaram 0 art. 5ำ, mas também permitirá a punição da própria pessoa jurídica por eles utilizada.

Explica José Anacleto (2015, p.277) que "a desconsideração da personalidade jurídica opera efeitos no plano da execução das penas, seja de multa administrativa, seja de perdimento de bens no âmbito judicial, ou em caso de reparação dos danos".

Nos artigos 50 do CC/2002 e 28, §5ำ do CDC, por exemplo, existem apenas as previsões de meios de aplicação da DJP, ou seja, dos critérios a serem observados no primeiro ou da sua aplicação direta no segundo. Em nenhum dos casos as sanções estão previstas de antemão, porque elas serão previstas relativamente aos ilícitos em que os sócios tenham incorrido.

Na Lei Anticorrupção, por sua vez, as sanções já são conhecidas e estão previstas no artigo 6ำ da LAC. Esta é, mais que a previsão da possibilidade da DPJ do art. 14, uma inovação ao passo que vincula a desconsideração às sanções contra a própria pessoa jurídica. 
Personalidade Acadêmica Homenageada:
Carlos Aurélio Mota de Souza (Universidade Ibirapuera - UNIB)

Esclarecendo-se, os casos de desconsideração previstos no ordenamento nacional apenas ensejam a responsabilização e consequente punição das pessoas físicas, enquanto que a Lei Anticorrupção atinge tanto as figuras dos sócios como as das pessoas jurídicas atuantes no mercado, aquelas que propiciaram a manutenção da corrupção no país.

Esta é uma importante inovação trazida pela Lei 12.846/2013, que pretende inibir a corrupção e, para isso, propõe-se a punir todos os envolvidos, mesmo os que representam apenas um rol de direitos dos sócios.

Talvez estejamos a caminho de novas mudanças no entendimento do que sejam as pessoas jurídicas, considerando-se que sua existência tem sido entendida, a partir desta lei, não apenas uma representação de direitos, mas o próprio sujeito de direitos que, inclusive, responde por seus atos. É, de fato, da pessoa jurídica inserida no contexto de seu ordenamento que trata a teoria atual, proporcionando a possibilidade dessa evolução na sua responsabilização em prol de uma sociedade menos injusta.

Importante para a responsabilização das pessoas jurídicas o fato de que as sanções destinadas a elas são, assim como os atos, previstos legalmente, proporcionando maior segurança jurídica e, principalmente, servindo como incentivo negativo ao cometimento de tais ilícitos.

Pode-se concluir, do exposto, que a LAC procura atingir tanto os responsáveis pelos atos ilícitos quanto os meios de que se utilizam, no intuito de diminuir, quiçá exterminar, a corrupção que assombra o setor público deste país.

\section{CONCLUSÃO}

A doutrina apresentada nesta pesquisa demonstrou que a personalidade jurídica foi, inicialmente, considerada como uma ficção legal, direito concedido pelo Estado. Em seguida passou a ser entendida como representação do indivíduo pela teoria da realidade objetiva. Esta última evoluiu para a teoria da realidade técnica, segundo a qual a personalidade jurídica deve ser analisada no contexto do 
Ordenamento Jurídico em que se encontrar, uma vez que os desejos do indivíduo passaram a ser representados pelas normas postas.

Este entendimento é o que vigora na doutrina nacional, positivada no Código Civil de 2002 que estabelece a forma de origem e extinção das pessoas jurídicas e estabelece as possibilidades de responsabilização dos sócios em cada tipo social.

Entendida como uma consequência da constituição da personalidade jurídica, pode-se concluir que a desconsideração, por sua vez, será necessária sempre que os sócios atuem de modo que a pessoa jurídica sirva como véu para o cometimento de atos em desacordo com sua finalidade, ou seja, que ocorra o abuso da personalidade, caracterizado por desvio de sua finalidade ou confusão patrimonial. Alinhada à história do instituto, a pesquisa apontou as teorias subjetiva e objetiva da Desconsideração da Personalidade Jurídica, de acordo com as quais, respectivamente, é necessária, ou não, a observação de requisitos para desconsiderar-se a pessoa jurídica.

Com previsão expressa de desconsideração em seu artigo 14, da pesquisa pode-se inferir que a Lei 12.846/2013 é resultado da assinatura de inúmeros tratados internacionais relativos ao combate à corrupção, principalmente nas esferas públicas e junto aos que com ela atuam; mas somente deixou de ser um projeto de lei pela força das manifestações populares que invadiram as ruas das principais cidades brasileiras em junho de 2013.

Nesta lei, chamada de Lei Anticorrupção, são previstos diversos atos lesivos à administração pública nacional e estrangeira. A partir da inobservância de algum deles é que a personalidade jurídica pode ser desconsiderada e, inclusive, responderá pelos atos praticados.

As previsões anteriores à LAC permitiam que a partir da desconsideração os sócios fossem punidos segundo os ilícitos que tivessem cometido. No entanto, a pesquisa aponta o fato de que a inovação da lei não está somente na possibilidade de desconsiderar objetivamente as pessoas jurídicas, mas sim na de puni-las por atos de seus representantes.

As sanções a que podem ser sujeitas as pessoas jurídicas são tipificadas e possuem rol exaustivo, assim como os atos lesivos que poderão ensejar as punições. Assim, tanto os ilícitos quanto a penalidade são conhecidos de antemão com o 
objetivo de diminuir a incidência dos casos de corrupção nos ambientes atingidos por tal lei.

Portanto, a pesquisa pode concluir que a Lei Anticorrupção não apenas é inovadora quanto à responsabilização objetiva das pessoas jurídicas, mas, e principalmente, é inovadora porque prevê punições destinadas especificamente a elas, enquanto sujeitos de direito.

Punir as pessoas jurídicas com castigos diretamente aplicados a elas é a grande novidade da Lei 12.846/2013, que investe contra a corrupção não apenas nas pessoas dos sócios/ dirigentes que cometeram os atos lesivos, mas no próprio meio pelo qual eles se utilizaram para praticar aqueles atos; punindo o fim e os meios da corrupção.

\section{REFERÊNCIAS}

BERTONCINI, Mateus Eduardo Siqueira Nunes. Dos Atos Lesivos à Administração Pública Nacional ou Estrangeira. In: SANTOS, José Anacleto Abduch; BERTONCINI, Mateus Eduardo Siqueira Nunes; COSTÓDIO FILHO, Ubirajara. Comentários à Lei 12.846/2013: Lei Anticorrupção. 2. ed. rev., atual. e ampl. - São Paulo: Editora Revista dos Tribunais, 2015

\section{Construção \\ O Microssistema de Proteção da Probidade Administrativa e a http://www.ceaf.mppr.mp.br/arquivos/File/o_microssistema.pdf Acesso em 30 Jan 2018}

Os princípios da proporcionalidade e razoabilidade na aplicação da Lei 8.429/1992: a insignificância no domínio da improbidade administrativa e o respeito à cidadania. Disponível em: http://www.ceaf.mppr.mp.br/arquivos/File/os_principios.pdf Acesso em 30 Jan 2018

BRASIL. Lei 8.078 de 11 de setembro de 1990. Dispõe sobre a proteção do consumidor e dá outras providências. Brasília, DF. Disponível em: http://www.planalto.gov.br/ccivil_03/Leis/L8078.htm. Acesso em: 22 Out. 2018

. Lei $n^{\circ}$ 12.846, de 1 de agosto de 2013. Dispõe sobre a responsabilização administrativa e civil de pessoas jurídicas pela prática de atos contra a administração pública, nacional ou estrangeira, e dá outras providências. Brasília, DF. Disponível em: http://www.planalto.gov.br/ccivil_03/_ato2011-2014/2013/lei/l12846.htm. Acesso em: 20 Out. 2018 
CAMPOS, Patrícia Toledo de. Comentários à Lei no 12.846/2013 - Lei anticorrupção. Revista Digital de Direito Administrativo, USP - Ribeirão Preto, v. 2, n. 1, 2015, p. 160-185

COELHO, Fábio Ulhoa. Desconsideração da Personalidade Jurídica. São Paulo: Revista dos Tribunais, 1989

COMPARATO, Fábio Konder. O poder de controle na sociedade anônima. São Paulo: Revista dos Tribunais, 1977

COSTÓDIO FILHO, Ubirajara. Disposições Gerais. In: SANTOS, José Anacleto Abduch; BERTONCINI, Mateus Eduardo Siqueira Nunes; COSTÓDIO FILHO, Ubirajara. Comentários à Lei 12.846/2013: Lei Anticorrupção. 2. ed. rev., atual. e ampl. - São Paulo: Editora Revista dos Tribunais, 2015

FARIAS, Cristiano Chaves de; ROSENVALD, Nelson. Curso de Direito Civil: Parte Geral e LINDB. São Paulo: Editora Atlas S.A., 2015

FERREIRA, Daniel; BERTONCINI, Mateus Eduardo Siqueira Nunes. Atividade Empresarial e Cidadania: Críticas à Lei Anticorrupção Brasileira. Revista Jurídica, Curitiba, v. 3, $n^{\circ}$. 44, 2016. pp. 451-472

JUSTEN FILHO, Marçal. Desconsideração da Personalidade Jurídica no direito brasileiro. São Paulo: Editora Revista dos Tribunais, 1987

KICHILESKI, Gustavo Carvalho; REIS, Clayton. Responsabilidade Civil Objetiva da Empresa por Atos de Corrupção à Luz da Lei 12.846/2013. Revista Jurídica UNICURITIBA, Curitiba, vol. 01, n. 46, 2016. pp. 119-145

KIÇULA, Diego do Nascimento. A responsabilidade solidária prevista na Lei 12.846/2013 frente ao fenômeno dos grupos de sociedades. $154 \mathrm{f}$. Dissertação. (Mestrado em Direito e Desenvolvimento) Escola de Direito de São Paulo da Fundação Getúlio Vargas, $2017 . \quad$ Disponível em https://bibliotecadigital.fgv.br/dspace/bitstream/handle/10438/18281/Disserta\%C3\%A 7\%C3\%A30\%20Diego\%20do\%20Nascimento\%20Ki\%C3\%A7ula\%20-\%20Final.pdf Acesso em 20 Out. 2018

OLIVEIRA, José Lamartine Correia de. A dupla crise da pessoa jurídica. São Paulo: Saraiva, 1979

PINHO, Clóvis Alberto Bertolini de. Desconsideração Administrativa da Personalidade Societária - Compatibilidades e Possibilidades da Lei Anticorrupção Revista Digital de Direito Administrativo, USP - Ribeirão Preto, v. 2, n. 1, 2015, p. 381-340

REQUIÃO, Rubens. Abuso de Direito e fraude através da personalidade jurídica. Revista dos Tribunais. São Paulo, volume 410, ano 58, p. 12-24, dezembro, 1969 
SANTOS, José Anacleto Abduch. Do Processo Administrativo de Responsabilização. In: SANTOS, José Anacleto Abduch; BERTONCINI, Mateus Eduardo Siqueira Nunes; COSTÓDIO FILHO, Ubirajara. Comentários à Lei 12.846/2013: Lei Anticorrupção. 2. ed. rev., atual. e ampl. - São Paulo: Editora Revista dos Tribunais, 2015

SILVA, Rita Daniela Leite da. O Compliance na Efetivação do Interesse Público. 117f. Dissertação (Mestrado em Direito Empresarial e Cidadania) UNICURITIBA Centro Universitário Curitiba, Curitiba: 2016 Disponível em: http://www.unicuritiba.edu.br/images/mestrado/dissertacoes/2016/Rita_Daniela_Leite _da_Silva.pdf Acesso em: 20 Out. 2018

TARTUCE, Flávio. Manual de Direito Civil: volume único. 6. ed. rev., atual. e ampl. Rio de Janeiro: Forense; São Paulo: Método, 2016 